\title{
Optimization of the process of aromatic and medicinal plant maceration in grape marc distillates to obtain herbal liqueurs and spirits
}

\author{
Raquel Rodríguez-Solana, ${ }^{a, b}$ Laura Vázquez-Araújo, ${ }^{a, b}$ José Manuel \\ Salgado, c José Manuel Domínguez ${ }^{\mathrm{a}, \mathrm{b}}$ and Sandra Cortés-Diéguez ${ }^{\mathrm{a}, \mathrm{b}^{*}}$
}

\begin{abstract}
BACKGROUND: Herbal liqueurs are alcoholic beverages produced by the maceration or distillation of aromatic and medicinal plants in alcohol, and are also highly valued for their medicinal properties. The process conditions, as well as the number and quantity of the plants employed, will have a great influence on the quality of the liqueur obtained. The aim of this research was to optimize these important variables.
\end{abstract}

RESULTS: A Box-Benhken experimental design was used to evaluate the independent variables: alcohol content, amount of plant and time during the experimental maceration of plants in grape marc distillate. Four plants were assessed, with the main compound of each plant representing the dependent variable evaluated with respect to following the evolution of the maceration process. Bisabolol oxide A in Matricaria recutita L., linalool in Coriander sativum L. and eucalyptol in Eucalyptus globulus Labill. were quantified using a gas chromatography-flame ionization detector. Glycyrrhizic acid in Glycyrrhiza glabra L was determined using a high-performance liquid chromatography-diode array detector. Other dependent variables were also evaluated: total phenolic content, color parameters and consumer preference (i.e. appearance).

CONCLUSION: The experimental designs allowed the selection of the optimal maceration conditions for each parameter, including the preference score of consumers: $70 \%(\mathrm{v} / \mathrm{v})$ of ethanol, $40 \mathrm{~g} \mathrm{~L}^{-1}$ plant concentration and a maceration process of 3 weeks.

(c) 2016 Society of Chemical Industry

Supporting information may be found in the online version of this article.

Keywords: aromatic and medicinal plant (AMP); Box-Benhken design; color parameters; maceration process; herbal liqueurs; herbal spirits

\section{INTRODUCTION}

Herbal liqueurs and spirits are traditional alcoholic beverages produced in different areas around the world by maceration or distillation of several aromatic and medicinal plants (AMP) in alcohol. In Galicia (northwest of Spain), these beverages have a long tradition and they are included in a new normative that has established different rules concerning the elaboration process, the raw materials (alcohol and plants) used, and the legal parameters that must be met for each type of herbal alcoholic beverage to ensure both their quality and consumer safety. Thus, herbal liqueurs have an alcohol content between $20 \%$ and $40 \%(\mathrm{v} / \mathrm{v})$ and sugar $\geq 100 \mathrm{~g}$ $\mathrm{L}^{-1}$, whereas, in herbal spirits, the alcohol and sugar content must be within the ranges: $37.5-50 \%(\mathrm{v} / \mathrm{v})$ and $\leq 100 \mathrm{~g} \mathrm{~L}^{-1}$, respectively. Twelve AMP have been used traditionally to elaborate these beverages, mint (Mentha piperita L. and Mentha pulegium L.), oregano (Origanum vulgare), rosemary (Rosmarinus officinalis L.), thyme (Thymus vulgaris L.), fennel (Foeniculum vulgare Mill.), cinnamon (Cinnamomum verum J. Presl), nutmeg (Myristica fragans Houtt), verbena (Aloysia citrodora), chamomile (Matricaria recutita L.), coriander (Coriandrum sativum L.), licorice (Glycyrrhiza glabra L.) and orange blossom (Citrus sinensis L.); however, since January 2012, any plant suitable for food can be used. ${ }^{1}$

Matricaria recutita L. or German chamomile is an important AMP in traditional and modern medicine. The flowers (containing the majority of the active compounds) and the essential oil have anti-inflammatory, spasmolytic, antiseptic, carminatic, sedative, diuretic, cholagoge and ulcer-protecting properties. ${ }^{2,3}$ The main compound is bisabolol oxide $A$, which contributes to

\footnotetext{
* Correspondence to: S Cortés-Diéguez, Department of Chemical Engineering, Faculty of Sciences, University of Vigo (Campus Ourense), As Lagoas s/n, 32004 Ourense, Spain.E-mail: smcortes@uvigo.es

a Department of Chemical Engineering, Faculty of Sciences, University of Vigo (Campus Ourense), As Lagoas s/n, 32004, Ourense, Spain

b Laboratory of Agro-food Biotechnology, CITI-Tecnópole, Tecnological Park of Galicia, San Cibrao das Viñas, Ourense, Spain

c Centre of Biological Engineering, University of Minho, Campus de Gualtar, 4710-057, Braga, Portugal
} 
the antispasmodic and anti-inflammatory effects of chamomile preparations. $^{3-5}$

Coriandrum sativum L. or coriander is another plant with a wide application in medicine, particularly the seeds, which are used to treat indigestion, rheumatism, pain in the joints, loss of appetite, convulsion, dyspeptic complaints, insomnia and anxiety, as well as being used against worms. Coriander is also widely used to flavor foods. Its main component is linalool. ${ }^{6-8}$ The International Joint Search Results Food and Agriculture Organization/World Health Organization Expert Committee on Food Additives (JECFA) established an acceptable daily intake (ADI) of 0-0.5 mg linalool $\mathrm{kg}$ body weight $(\mathrm{bw})^{-1}$ day $^{-1}$. $^{9}$

Licorice is the name of the root obtained after drying and processing the plant G. glabra L. It is widely used as a food additive, as well as in medicine preparations aiming to treat symptoms of viral respiratory tract infections and hepatitis. ${ }^{10,11}$ The main active compound is glycyrrhizic acid (GA), which has anti-inflammation, anti-ulcer, anti-hepatotoxic and antivirus activities, and is used to treat patients with AIDS. However, daily intake for longer than 6 weeks ( $>1 \mathrm{~g} \mathrm{GA} \mathrm{day}^{-1}$ ) can induce a syndrome of sodium retention and potassium excretion, causing edema and hypertension. ${ }^{10}$

Besides these traditional plants, it is interesting to evaluate other alternative plants used for preparing herbal alcoholic drinks. In this sense, approximately $12 \%$ of the wooded area of Galicia is Eucalyptus globulus Labill. The essential oil of leaves, a byproduct of tree cutting, has medicinal properties because it exerts rubefacient, local anaesthetic, spasmolytic, antiphlogistic, secretolytic and secretomotoric effects, although it is also used in aromatherapy and perfumes and has been approved as a food additive. ${ }^{11-14}$ However, the ingestion of a few milliliters of essential oil may cause severe symptoms of intoxication and may lead to death. ${ }^{14}$ Eucalyptol is the main compound found in the essential oil of Eucalyptus ${ }^{11,13}$ with a tolerable daily intake of $0.1 \mathrm{mg} \mathrm{kg}^{-1} .^{15}$

The present study investigated the maceration of the plants previously named because they contain valuable compounds in different parts of the plant that are transferred into spirits: flowers of $M$. recutita L., seeds of $C$. sativum L., roots of G. glabra L., and leaves of E. globulus Labill. Moreover, they are plants of great importance with respect to the herbal spirits and liqueurs produced in this region and their interaction with the distillate has not been studied to date.

A Box-Behnken experimental design was carried out to evaluate the independent variables [\% ( $/ \mathrm{v}$ ) ethanol of the grape marc distillate, ratio of quantity of plant/alcohol volume (plant concentration) and time of maceration] on the main volatile compounds: chamomile, coriander and eucalyptus, as well as the main phenol in licorice. Additionally, the total phenolic content (TP) (as a result of its importance with respect to the biological properties of these plants), ${ }^{16}$ the parameters of color (hue and color intensity) and consumer preference were also evaluated as dependent variables.

The optimal conditions will be useful for the liqueur industry when considering which variables have the greatest influence in the development of the final product and in regulating the concentration of certain compounds that can have toxic effects at a high dose on human health.

\section{MATERIALS AND METHODS}

\section{Samples}

Glycyrrhiza glabra L., M. recutita L., C. sativum L. and E. globulus Labill. were purchased from a phytotherapy company (Spain). The plants were dried and vacuum packed. The plantation was certified as organic by the Organic Farming Council of Castilla and Leon (CAECYL) in accordance with EU regulations. Plants were grown in a continental climate zone and were cultured, collected and dried in appropriate season in accordance with the supplier's instructions. The grape marc distillate was provided by a local winery.

\section{Reagents}

All standards (linalool, bisabolol oxide A, eucalyptol, glycyrrhizic acid and absolute ethanol and methanol solvents) were purchased from Sigma-Aldrich (Steinheim, Germany) (>95\% purity). Acetonitrile [for high-performance liquid chromatography (HPLC), 99.9\%], trifluoroacetic acid (99.8\%) and purified and calcined siliceous earth (USP-NF) RRS-CODEX were purchased from Panreac (Barcelona, Spain). Alkane standard solution C8-C20 was purchased from Fluka (Steinheim, Germany).

\section{Methods}

Characterization of M. recutita L., C. sativum L. and E. globulus Labill.: extraction by accelerated solvent extraction (ASE) and analysis by gas chromatography-mass spectroscopy (GC-MS)

The selection of the most representative compound in each plant (i.e. to follow the evolution of the maceration during the experimental design) was carried out after analysis by GC-MS of the corresponding essential oil previously obtained by ASE. This extraction was performed using a Dionex extractor (ASE 350) obtained from Vertex Technics (Barcelona, Spain) in accordance with the procedure described by Rodríguez-Solana et al. ${ }^{17}$ The volatile profile of the methanolic extracts obtained was determined using an Agilent 7820A gas chromatograph (Agilent, Santa Clara, CA, USA) equipped with an Agilent 5975 series MSD and a nonpolar HP-5MS column (5\% diphenyl, 95\% dimethylpolysiloxane, length $30 \mathrm{~m}$, inner diameter $0.25 \mathrm{~mm}$, film thickness $0.25 \mathrm{~mm}$ ) with a ramp temperature and operating in the electron impact mode $(70 \mathrm{eV})$ and with transfer line and ion source temperatures maintained at $230^{\circ} \mathrm{C}$. The injector temperature was maintained at $250{ }^{\circ} \mathrm{C}$, whereas that of the quadrupole was $150^{\circ} \mathrm{C}$. Carrier gas used was $\mathrm{H}_{2}$ (from a Hydrogen generator AD-180 Series; CINEL,

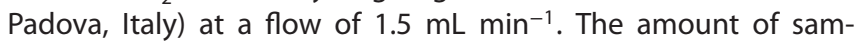
ple injected was $0.5 \mu \mathrm{L}$ (in splitless mode). The oven temperature was programmed as: $50-220^{\circ} \mathrm{C}\left(2.5^{\circ} \mathrm{C} \mathrm{min}-1\right), 220-300{ }^{\circ} \mathrm{C}$ $\left(10^{\circ} \mathrm{C} \mathrm{min}^{-1}\right)$. The identification procedure was as described by Rodríguez-Solana et al. ${ }^{17}$

\section{Plants macerated preparation}

Approximately $4 \mathrm{~L}$ of grape marc distillate was necessary for the preparation of the plants macerated in the fifteen experiments (with duplicates) during the Box-Benhken design. Samples were evaluated with different alcohol contents $(70 \% \mathrm{v} / \mathrm{v}, 55 \% \mathrm{v} / \mathrm{v}$ and $40 \% \mathrm{v} / \mathrm{v}$ ) and spirits with $55 \% \mathrm{v} / \mathrm{v}$ and $40 \% \mathrm{v} / \mathrm{v}$ were prepared by dilution of the initial distillate $(70 \% \mathrm{v} / \mathrm{v})$ with distilled water. Different plant quantities were weighed (4.8, 3 and $1.2 \mathrm{~g}$ ) and added to $120 \mathrm{~mL}$ of the corresponding distillate to obtain different concentrations of plants in the macerates $\left(40,25\right.$ and $10 \mathrm{~g} \mathrm{~L}^{-1}$, respectively). The head space was avoided with glass beads. Opaque bottles were used, which were kept in the dark. According to the experimental procedure, macerates were filtered under vacuum during the first, third or fifth week and kept at $-40{ }^{\circ} \mathrm{C}$ in the dark to avoid evolution in the final product.

Quantification of principal components of M. recutita L., C. sativum L. and E. globulus Labill. by a GC-flame ionization detector (FID) and of G. glabra L. by a HPLC-diode array detector (DAD) 


\begin{tabular}{|lcccccc|}
\hline \multicolumn{2}{|l}{ Table 1. Parameters of the calibration curves } & & & & \\
Compound & Concentration range $\left(\mathrm{mg} \mathrm{L}^{-1}\right)$ & Calibration curve & $r^{2}$ & LOD $\left(\mathrm{mg} \mathrm{L}^{-1}\right)$ & LOQ (mg L-1) & Technique \\
\hline Glycyrrhizic acid & $50-575$ & $y=14.46 x+19.267$ & 1 & 6 & 19 & HPLC-DAD \\
Eucalyptol & $50-500$ & $y=1.0577 x-4.4563$ & 0.999 & 23 & 76 & GC-FID \\
Linalool & $10-200$ & $y=1.2543 x-0.7361$ & 0.9989 & 1.5 & 18 \\
Bisabolol oxide A & $5-40$ & $y=1.1293 x+2.5543$ & 0.9923 & 4 & GC-FID \\
\hline
\end{tabular}

The quantification of bisabolol oxide A, linalool and eucalyptol of macerated plants was carried out using an Agilent 7890A GC-FID. The column used was a HP-INNOWax (polyethylene glycol, length $60 \mathrm{~m}$, inner diameter $0.25 \mathrm{~mm}$, film thickness, $0.25 \mu \mathrm{m}$ ). The volume of the samples (previously diluted) injected was $1 \mu \mathrm{L}$. The oven temperature was programmed as: $60^{\circ} \mathrm{C}$ for $15 \mathrm{~min}$, and then $60^{\circ} \mathrm{C}$ to $230^{\circ} \mathrm{C}$ at $3{ }^{\circ} \mathrm{C} \mathrm{min}^{-1}$. Injector and detector temperatures were $250^{\circ} \mathrm{C}$ and $260^{\circ} \mathrm{C}$. The flow of $\mathrm{H}_{2}$ was: $1 \mathrm{~mL} \mathrm{~min}^{-1}$. Mode split has a split ratio of 10:1. The quantification of glycyrrhizic acid was carried out using an Agilent 1200 series HPLC system equipped with a UV-visible DAD (model G1315B). The column used was Zorbax SB-Aq reverse-phase column $5 \mu \mathrm{m}$ (inner diameter $4.6 \mathrm{~mm}$, length $150 \mathrm{~mm}$ ) (Agilent) with a guard column. The wavelength used in the DAD was $254 \mathrm{~nm}$ because the standard spectrum presented a maximum band at this wavelength. The mobile phases were water (A) and acetonitrile (B), both with $0.05 \%(w / w)$ of trifluoroacetic acid. The gradient elution was: $20 \% \mathrm{~B}(t=0 \mathrm{~min})$ to $40 \% \mathrm{~B}(t=10$ $\mathrm{min}$ ) and then $5 \mathrm{~min}$ at this proportion, $40 \%$ B to $50 \%$ B in $1 \mathrm{~min}$, and then $50 \% \mathrm{~B}$ to $20 \% \mathrm{~B}$ in $1 \mathrm{~min}$, and $3 \mathrm{~min}$ at this proportion. The injection volume was $20 \mu \mathrm{L}$. The flow rate was of $0.8 \mathrm{~mL} \mathrm{~min}{ }^{-1}$.

Table 1 shows the range of the concentration prepared for standards, the equation of the calibration curve, the coefficient of determination $\left(r^{2}\right)$, the limits of detection (LOD) (Eqn 1) and the limit of quantification (LOQ) (Eqn 2) and the technique used for the analysis of the respective compound:

$$
\mathrm{LOD}=\frac{3 \times S y x}{m}
$$

and

$$
\mathrm{LOQ}=\frac{10 \times S y x}{m}
$$

where $S_{y x}$ is the estimation of the standard deviation of the regression line and $m$ is the slope of the calibration curve.

\section{Total phenols (method of Folin-Ciocalteu)}

The TP analysis of the macerations was carried out using the Folin-Ciocalteau method described by Otles et al. ${ }^{18}$ In this method, there is a chemical reaction (reduction) comprising the transfer of electrons in the alkaline medium from phenolic compounds present in the plant extracts to phosphomolyb$\mathrm{dic} /$ phosphotungstic acid complexes (blue products) that were measured with a spectrophotometer at $760 \mathrm{~nm} .{ }^{19,20}$ A calibration curve of gallic acid was performed and the results are expressed in mg gallic acid equivalents (GAE) g dry plant ${ }^{-1}$. All determinations were performed in duplicate.

\section{Color parameters and consumer study}

Hue is the property of light by which the color of an object is classified by humans into group wavelengths (in reference to the spectrum) of color categories, such as red, blue, green, or yellow. ${ }^{21}$ The color intensity is a scale of the lightness of the color, termed its brightness. Color intensity, absorbance measurements of undiluted samples at a wavelength of 420 (yellow), 520 (red) and $620 \mathrm{~nm}$ (violet), and hue were also evaluated employing an optical quartz 1-mm path length cuvettes and a UV-visible Cintra 6 Spectrophotometer (GBC Scientific Equipment, Madrid, Spain). The equations for the color intensity (Eqn 3) and hue (Eqn 4) (obtained according to the EEC method, 1990) are:

$$
\begin{gathered}
\text { Color intensity }(\mathrm{Cl})=A_{420}+A_{520}+A_{620} \\
\text { Hue }=A_{420} / A_{520}
\end{gathered}
$$

With the aim of studying the consumer preference of appearance of the different samples, a consumer survey was conducted. Over 52 participants ( $40 \%$ men, $60 \%$ women) evaluated the appearance of the 15 experiments (samples). The consumers were aged from 18 to 70 years, and only individuals who were familiar with herb liqueurs participated in the study (i.e. those who purchase or consume liqueurs at least once per week). Participants were asked to rate how much did they like the color of the samples using a intensity scale of 1 to 9 ( $1=$ extremely dislike; $5=$ neither like nor dislike; $9=$ extremely like). Consumers then answered a Just-About-Right (JAR) question about color (1 = extremely light; 5 = just-about-right; 9 = extremely intense). Just About Right (JAR) is a sensorial scale that measure the appropriateness of the level of a specific attribute, in this case, color, in a product. Samples were codified with three-digit codes and the order of the samples was randomized for each consumer.

\section{Box-Behnken response surface methodology}

An experimental design was carried out for each plant (C. sativum L., M. recutita L., E. globulus Labill. and G. glabra L.) to optimize the independent variables [concentration of plant $\left(\mathrm{g} \mathrm{L}^{-1}\right)$, time (weeks) and ethanol (\%)] that affect the maceration of plants. Each experimental design consisted of three factors and three levels, including three replicates at the center point (0), providing a second-order response surface. The dependent variables studied were the concentration of each main component $\left(\mathrm{mg} \mathrm{L}^{-1}\right)$, TP $(\mathrm{mg}$ GAE g dry plant $\left.{ }^{-1}\right)$, color intensity $(\mathrm{Cl})$ and hue of each plant. The coded value was $(-1,0,1)$ and uncoded values of each variable were: concentration of plant $\left(x_{1} ; 10,25,40 \mathrm{mg} \mathrm{L}^{-1}\right)$, time $\left(x_{2} ; 1,3,5\right.$ weeks) and ethanol ( $\left.x_{3} ; 40 \%, 55 \%, 70 \%\right)$. A polynomial quadratic equation was fitted to correlate the response variables to the independent variables:

$$
\begin{aligned}
y & =b_{0}+b_{1} x_{1}+b_{2} x_{2}+b_{3} x_{3}+b_{12} x_{1} x_{2} \\
& +b_{13} x_{1} x_{3}+b_{23} x_{2} x_{3}+b_{11} x_{1}^{2}+b_{22} x_{2}^{2}+b_{33} x_{3}^{2}
\end{aligned}
$$

where $y$ is the predicted response, $b_{0}$ is the model constant; $x_{1}, x_{2}$ and $x_{3}$ are independent variables (coded); $b_{1}, b_{2}$ and $b_{3}$ are linear coefficients; $b_{12}, b_{13}$ and $b_{23}$ are cross-product coefficients; and $b_{11}$, 
$b_{22}$ and $b_{33}$ are the quadratic coefficients. Dependent variables were optimized using commercial software (Solver Add-in for Excel 2007; Microsoft, Redmond, WA, USA). For statistical calculations, the independent variables $\left(x_{\mathrm{i}}\right)$ were coded as $x_{\mathrm{i}}$ according to the equation:

$$
x_{i}=\frac{\left(x_{\mathrm{i}}-x_{0}\right)}{\delta x}
$$

where $x_{\mathrm{i}}$ is the dimensionless coded value of the independent variable, $x_{0}$ is the value of independent variable at the center point and $\delta x$ is the step change. The goodness-of-fit of the regression model was obtained from the coefficient of determination $r^{2}$ and the adjusted coefficient of determination. For each run, predicted values were calculated from the regression equation (Eqn 5).

\section{RESULTS AND DISCUSSION}

\section{Characterization of $M$. recutita $L$., C. sativum L. and E. globulus} Labill.: extraction by ASE and analysis by GC-MS

The volatile profile characterization of the chamomile, coriander and eucalyptus extracts was performed to select the compound for use as a dependent variable during the experimental design. A pretreatment step of extraction was carried out with the accelerated solvent extraction technique. This technique is reported to be a good way of characterizing the volatile profile of plant extracts in many studies. ${ }^{17,22-24}$ Table 2 shows the compounds identified, the family they belong to, the retention index (RI) reported in literature from the National Institute of Standards and Technology, and the RI calculated as described by Rodríguez-Solana et al. ${ }^{17}$ The semiquantification of each plant extract is shown in Table 3. As can be seen, the main compound was bisabolol oxide A for M. recutita L. (64\%); linalool for Coriandrum sativum L. (71\%); and eucalyptol for Eucalyptus globulus Labill. (41\%). Consequently, these compounds were chosen as dependent variables in the Box-Behnken design to follow the influence of the independent variables on maceration.

\section{Optimization of the main components of each plant using a Box-Behnken design}

The study of extraction parameters is important because changes in these parameters can affect the quality and extraction yield of the individual extractable compounds. ${ }^{25}$

Box-Behnken designs were carried out to optimize the parameters of the macerated plants and to obtain the maximum concentration of the main components of each AMP.

Table 4 shows the observed and predicted values by the model. The difference between both values was low. There were variations in the concentration of each component in the different experiments; thus, the parameters of macerated plants had an effect on the extraction of these components. A Pareto chart (Fig. 1) was used to conduct a statistical analysis of the experimental data. The concentration of the plant had a higher positive effect on dependent variables compared to ethanol and time. The effect of time was not significant, except for glycyrrhizic acid extracted from G. glabra L. which was significant at $95 \%$, and time presented a negative significant effect $(P<0.05)$ on this compound extraction, with 1 week being sufficient to achieve the maximum concentration of glycyrrhizic acid.

Regression coefficients and statistical parameters are provided in the Supporting information (Table S1). $r^{2}$ ranged from 0.9696 to 0.9873 indicating high correlations between the observed and predicted values, and the statistical parameters confirmed the significance of the model with values of adjusted $r^{2}$ ranging from 0.9149 to 0.9644 , with the significance of each regression coefficient also being indicated by asterisks.

Figure 2(a) to (d) depicts the three-dimensional surface plots of the main component extracts of each plant as a function of the concentration of plant and ethanol content, whereas time was fixed at its middle level ( 3 weeks). These plots are the projection of the response surface in a three-dimensional plane. The concentration of the main component of each plant increased gradually with an increasing quantity of plant and ethanol, and the concentration of the plant exerted a greater influence on compound extractions than the ethanol content. In experiments with the highest quantity of plant, the effect of ethanol was more important. For example, in the extraction of linalool from $C$. sativum $L$. an increase in ethanol from $40 \%$ to $70 \%(\mathrm{v} / \mathrm{v})$ at the highest concentration of plant (40 $\mathrm{g} \mathrm{L}^{-1}$ ) and a mid-level time (3 weeks) resulted in an increase of the linalool concentration from $67.79 \mathrm{mg} \mathrm{L}^{-1}$ to $173.53 \mathrm{mg} \mathrm{L}^{-1}$.

The parameters of maceration were optimized to obtain the maximum concentration of each component. The optimal conditions of concentration of plant, time and ethanol as independent variables are shown in Table 5. For dependent variables the optimal values were $154.35 \pm 5.72 \mathrm{mg} \mathrm{L}^{-1}$ for linalool concentration. The International JECFA established an ADI of $0-0.5 \mathrm{mg}$ linalool $\mathrm{kg} \mathrm{bw}^{-1} \mathrm{day}^{-1}$; assuming an adult weight of $70 \mathrm{~kg}$, which consumes no more than $50 \mathrm{~mL}^{\text {day }^{-1}}$, we achieved an ADI of $0.11 \pm 0.00 \mathrm{mg} \mathrm{kg} \mathrm{bw}^{-1}$ day $^{-1}$, which is within the range of the permitted ADI.

Eucalyptol presented an optimal concentration of $922.65 \pm 48.25$ $\mathrm{mg} \mathrm{L}^{-1}$ and, assuming the above data on weight and quantity $(\mathrm{mL})$ of beverage consumed, the tolerable daily intake (TDI) was of $0.66 \pm 0.03 \mathrm{mg} \mathrm{kg} \mathrm{bw}^{-1}$, in agrement with the TDI recommended by De Vincenzi et al. ${ }^{15}$ of $0.1 \mathrm{mg} \mathrm{kg}^{-1}$. In this case, the TDI is six times greater than the value recommended. Therefore it is necessary to avoid the optimal independent variables, thus preventing excessive eucalyptol extraction.

The maximum concentration of glycyrrhizic acid in plant macerates was $1812.3 \pm 96.36 \mathrm{mg} \mathrm{L}^{-1}$ with a daily intake (DI) of $0.001 \pm 0.000 \mathrm{~g} \mathrm{~kg} \mathrm{bw}^{-1}$ day $^{-1}$. Such a Dl is much lower than the amount ( $>1 \mathrm{~g}$ glycyrrhizic acid day $^{-1}$ ) needed to induce a syndrome of sodium retention and potassium excretion, resulting in edema and hypertension.

In all plants, the maximum concentration of plant $\left(40 \mathrm{~g} \mathrm{~L}^{-1}\right)$ led to the maximum extraction of the main components; maximum ethanol content was also the optimal value, except for glycyrrhizic acid extracted from G. glabra L., which was lower (57.52\%). In addition, short periods of time were adequate to achieve maximum extraction, except for eucalyptol, for which maximum extraction was obtained in 5 weeks. To confirm the optimal value, duplicate extractions with optimized parameters for each plant were performed. These values were found to be similar to the values predicted by the model.

In general, the behavior was similar regardless of the part of the plant used: a high concentration of plant and alcohol content and a short time were needed for the extraction of the main plant components. Only for the eucalyptus was the maximum time ( 5 weeks) required to enable penetration inside the leaves and extraction of the maximum amount of its main component, although the TDI of eucalyptol was six times greater than the recommended value (Table 5 ). But this TDI value was too high, even with a sufficiently short time (Table 4, run 2 ( 1 week) and run 8 (3 weeks). 


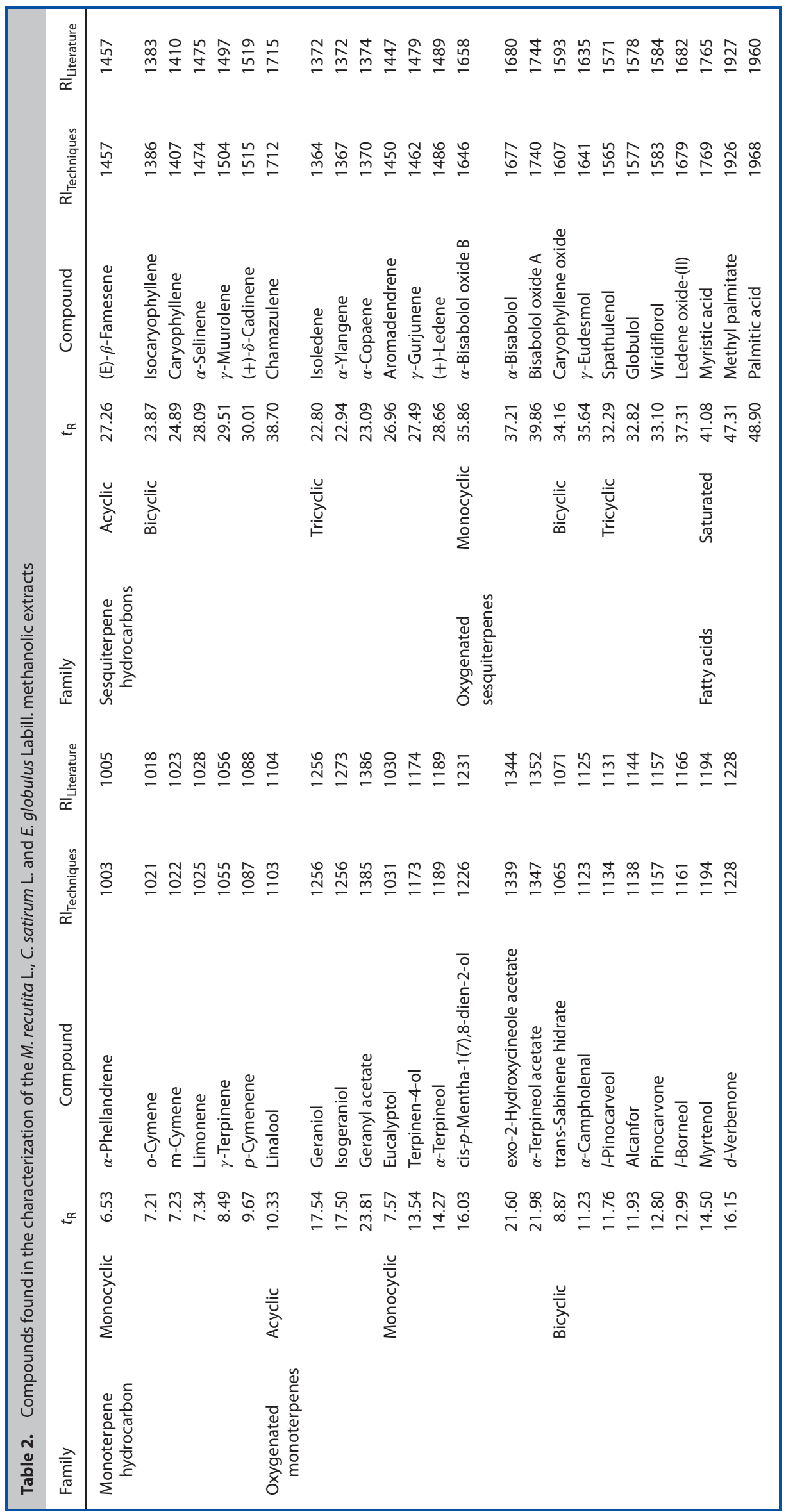


Table 3. Characterization of C. sativum L. seeds, E. globulus Labill. leaves and M. recutita L. flowers methanolic extracts volatile profile

\begin{tabular}{|c|c|c|c|c|c|c|}
\hline \multirow[b]{2}{*}{ Compound } & $\begin{array}{l}\text { Coriandrum } \\
\text { sativum L. }\end{array}$ & $\begin{array}{l}\text { Eucalyptus } \\
\text { globulus Labill. }\end{array}$ & \multirow[b]{2}{*}{ Compound } & \multirow[t]{2}{*}{$\begin{array}{c}\text { Coriandrum } \\
\text { sativum L. }\end{array}$} & \multirow{2}{*}{$\begin{array}{c}\begin{array}{c}\text { Eucalyptus } \\
\text { globulus Labill. }\end{array} \\
\text { Area (\%) }\end{array}$} & \multirow[t]{2}{*}{$\begin{array}{c}\text { Matricaria } \\
\text { recutita } \mathrm{L} .\end{array}$} \\
\hline & & a (\%) & & & & \\
\hline$\alpha$-Phellandrene & & 0.57 & (E)- $\beta$-Famesene & & & 23.41 \\
\hline o-Cymene & & 1.22 & Isocaryophyllene & & 0.57 & \\
\hline m-Cymene & 0.61 & & Caryophyllene & 0.13 & & \\
\hline Limonene & 0.60 & 2.04 & $\alpha$-Selinene & & 0.76 & \\
\hline$\gamma$-Terpinene & 2.48 & 0.17 & $\gamma$-Muurolene & & 0.55 & \\
\hline p-Cymenene & & 0.34 & $(+)-\delta$-Cadinene & & 0.31 & \\
\hline Linalool & 70.60 & & Chamazulene & & & 3.64 \\
\hline Geraniol & & 0.60 & Isoledene & & 0.52 & \\
\hline Isogeraniol & 1.42 & & $\alpha$-Ylangene & & 0.30 & 0.11 \\
\hline Geranyl acetate & 3.80 & & $\alpha$-Copaene & & 0.15 & \\
\hline Eucalyptol & & 41.23 & Aromadendrene & & 6.03 & \\
\hline Terpinen-4-ol & 0.27 & 0.53 & $\gamma$-Gurjunene & & 0.55 & \\
\hline$\alpha$-Terpineol & 0.34 & 2.58 & (+)-Ledene & & 5.15 & \\
\hline cis-p-Mentha-1(7),8-dien-2-ol & & 0.54 & $\alpha$-Bisabolol oxide B & & & 5.38 \\
\hline exo-2-Hydroxycineole acetate & & 0.34 & $\alpha$-Bisabolol & & & 1.73 \\
\hline$\alpha$-Terpineol acetate & & 4.52 & Bisabolol oxide A & & & 64.13 \\
\hline trans-sabinene hidrate & 0.11 & & Caryophyllene oxide & & 0.89 & \\
\hline$\alpha$-Campholenal & & 0.11 & $\gamma$-Eudesmol & & 5.05 & \\
\hline I-Pinocarveol & & 2.54 & Spathulenol & & & 1.60 \\
\hline Alcanfor & 2.65 & & Globulol & & 15.35 & \\
\hline Pinocarvone & & 1.18 & Viridiflorol & & 3.99 & \\
\hline I-Borneol & 1.32 & 0.26 & Ledene oxide-(II) & & 0.34 & \\
\hline Myrtenol & & 0.35 & Myristic acid & 1.15 & & \\
\hline$d$-Verbenone & & 0.39 & Methyl palmitate & 0.35 & & \\
\hline & & & Palmitic acid & 14.16 & & \\
\hline
\end{tabular}

\section{Optimization of TP extraction of each AMP by a Box-Behnken design}

Table 4 shows the value of TP for each AMP studied. The regression coefficients for each of the factor and lineal interactions, as well as the significance and the value of the regression coefficients, are shown in the Supporting information (Table S1). The effect of ethanol in total phenols was significant and positive for three plants; the effect of time was significant for E. globulus Labill. and the effect of the concentration of plant was significant for $G$. glabra L. The optimal conditions are shown in Table 5. There were differences in the optimal parameters between three plants. In $E$. globulus Labill. a lower amount of plant was necessary to obtain the maximum extraction of total phenols; however, in G. glabra L. the highest concentration of the plant was the optimal value. In three plants, mid-level values of time were optimal for the total phenol extraction. The maximum concentration of ethanol (70\%) favored total phenol extraction in M. recutita L. and E. globulus Labill.

As observed, the maximum extraction of TP with the optimal conditions chosen for the main compound was from the leaves of E. globulus Labill. $\left(36.12 \pm 1.12 \mathrm{mg} \mathrm{GAE} \mathrm{g} \mathrm{dry} \mathrm{plant}^{-1}\right)$ followed by the flowers of $M$. recutita $L$. (three-fold lower). These results agree with the results reported by Dudonne et al. ${ }^{26}$ where a comparison of different parts of the plants extracted with water as a solvent showed the value of TP extracted from Eucalyptus leaves $\left(113.68 \pm 0.33 \mathrm{mg} \mathrm{GA} \mathrm{g} \mathrm{dry}\right.$ plant $\left.^{-1}\right)$ was approximately three-fold lower than the value from flowers of $M$. recutita $L$. The roots of G. glabra L. presented a quantity of TP that was four-fold lower than that for Eucalyptus. The grape marc distillate could not extract a significant quantity of TP from the seeds of $C$. sativum $L$. Vongsak et al..$^{27}$ evaluated the maceration of a medicinal plant and compared this with other extraction methods, such as squeezing, decotion, percolation and Sohxlet extraction. It was observed that maceration with $70 \%(\mathrm{v} / \mathrm{v})$ ethanol led to maximum amounts of TP. The positive effect of ethanol is also shown Fig. 2(e) to (g). It can be deduced that the highest extraction of total phenols is obtained with a high ethanol concentration.

\section{Optimization of color parameters of each plant macerated by the Box-Behnken design}

Color plays an important role because it affects the consumer perception of quality. ${ }^{28}$ The monitoring and recording of color is useful for purposes of product consistency and quality control, and is also an indicator for many issues related to liqueur development. The characteristic color of herbal liqueur and spirit ranges from straw yellow to greenish yellow. Human vision is limited to a small region of the spectrum but the spectrophotometers can measure wavelengths in the UV and visible spectral regions. ${ }^{29}$ Statistical optimization of maceration parameters as a result of the experimental design offers the opportunity to select conditions maximizing the color parameters from the color measurements made by spectrophotometer. Observed and predicted values of $\mathrm{Cl}$ and hue of C. sativum L., M. recutita L., E. globulus Labill. and G. glabra L. are shown in Table 6. Lower differences between observed and 


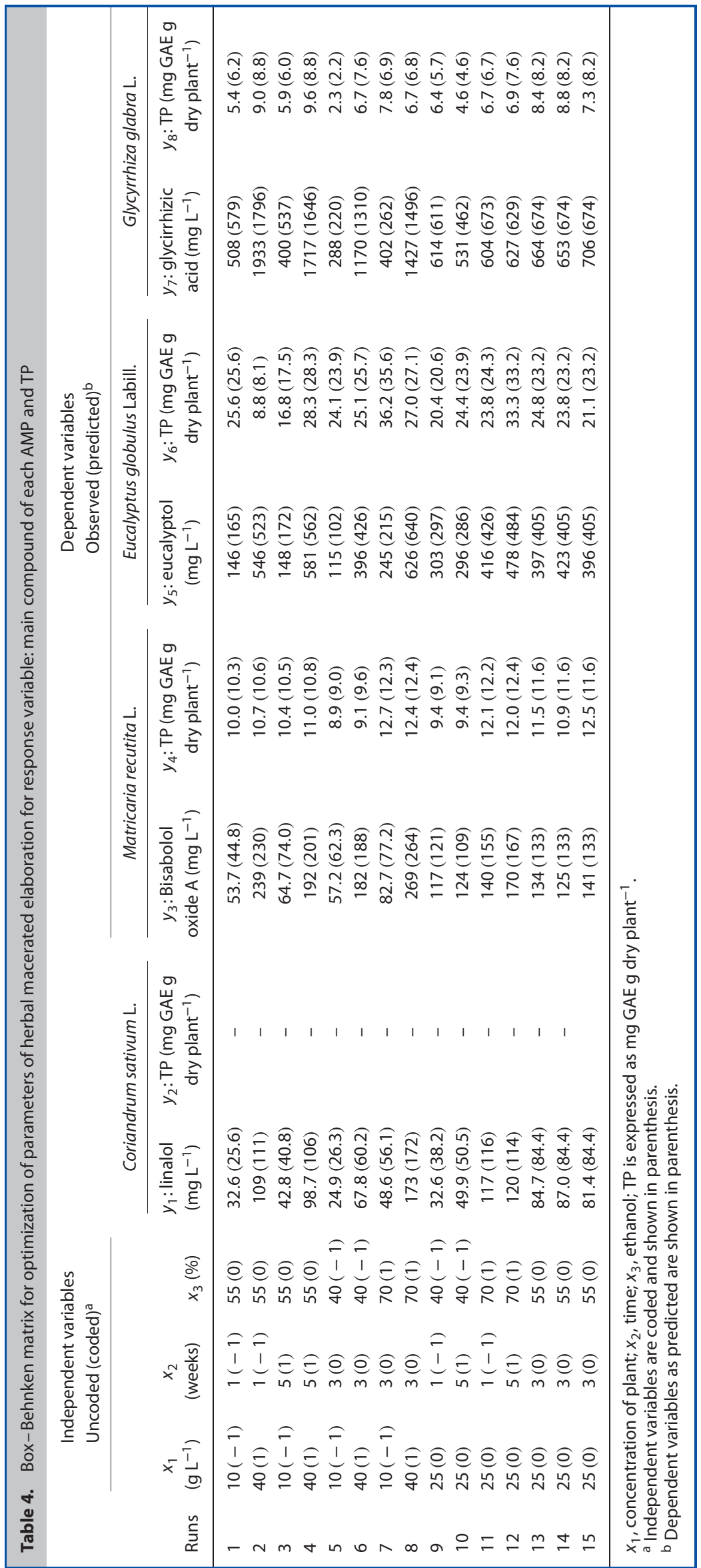



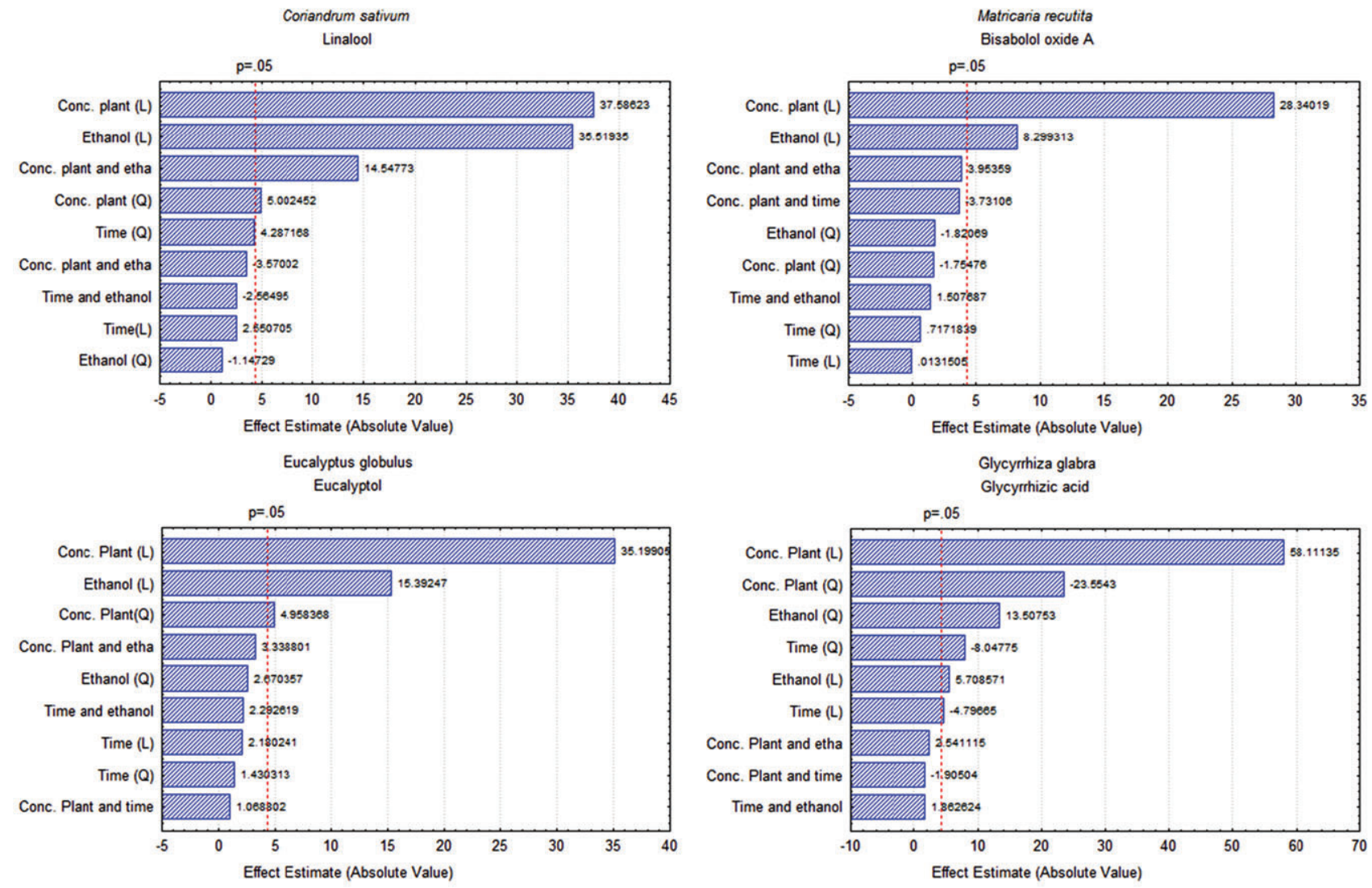

Figure 1. Pareto chart for principal components extracted from each plant as a function of independent variables.

predicted values were observed. A general satisfactory adjustment of the model with regression coefficients and the statistical part of the color parameters are presented in the Supporting information (Table S2) and the variables that affected the extraction of color were the concentration of plants and ethanol in all plants. Table 5 shows the optimal conditions for both color parameters. In each plant, there was difference between the optimal conditions for maximum $\mathrm{Cl}$ and hue. Knowing that hue is the relationship between $A_{420 /} A_{520}$ and also that $A_{420}$ indicates compounds that have a maximum of absorbance at this wavelength presenting a yellow color, whereas $A_{520}$ indicates the compounds that have the maximum absorbance at this wavelength and have a red color, ${ }^{30}$ and as a result of the regulation ${ }^{1}$ establishing that the color from straw yellow to greenish yellow is allowed for these kind of beverages, the optimal hue value for the experiments will be that with a higher absorbance at $A_{420}$ presenting the yellow color. Lower concentrations of plant led to maximum hue value in $C$. sativum $\mathrm{L}$. and $M$. recutita $\mathrm{L}$.; however, the optimal value of $\mathrm{Cl}$ was the highest amount of plant. In all plants, the highest concentration of ethanol favored the color extraction, except for $\mathrm{Cl}$ in C. sativum L. Long periods of time improved the color extraction from all plants, except for the hue parameter of E. globulus Labill. The experimental results are presented in the form of surface plots in Fig. 3(a) to (I), and the same effect is observed. In general, lower levels of the concentration of plant and ethanol support low levels of parameter colors, except for Hue values of C. sativum L. and M. recutita L. (Fig. 3b, e).

Because color is an important driver for consumer preference, ${ }^{31}$ a small consumer study was conducted to determine the overall preference with respect to the appearance of the different experiments. Significant differences $(P<0.05)$ were found among the color preferences of the samples (Table 7), with the most preferred sample being the one made with G. glabra L. $40 \%$ (v/v) ethanol, 1 week. This sample obtained an average score of 7.7 (1-9 preference scale). Values close to 7 were achieved in samples made with C. sativum $L$. and $M$. recutita $L$, with both of them extracted using $40 \%$ (v/v) ethanol. Samples made with E. globulus Labill. appeared to have a lower preference among consumers. Just About Right (JAR) responses indicated that color was 'too dark' for consumers in some of the experiments.

With the aim of determining whether variability in consumer responses could be explained by the independent variables (plant concentration, ethanol percentage and time), the data were tested as dependent variables in the experimental design. The $r^{2}$ values indicated that $95.48-99.07 \%$ of the variability could be explained by the independent factors; therefore, the maceration parameters could be used as predictors of color preference by consumers. The effects of concentration of plant and ethanol content were significant at $95 \%$. The effect of time was not significant at $95 \%$. Table 6 shows the sample preferred by consumers for each plant.

The lowest ethanol concentrations lead to the highest color preference by consumers. This effect was in contrast to the effect of ethanol observed in spectrophotometric parameters, where a higher concentration of ethanol favored the extraction of color. On the other hand, the concentration of plant had a positive effect on color preference. Parpinello et al. ${ }^{31}$ observed that the majority of consumers preferred a high color intensity in the color evaluation of wines. However, the results of the present study showed that experiments with the highest color intensity were not the samples liked most by consumers. 
(a)

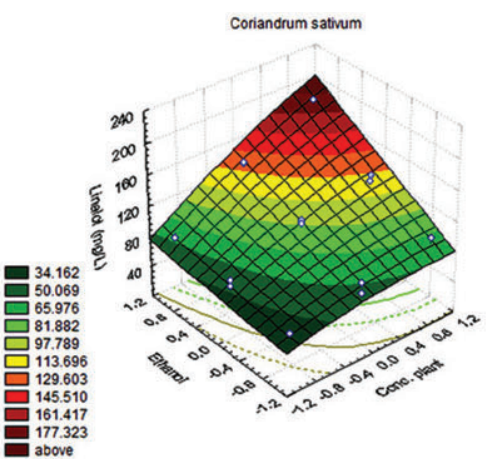

(c)

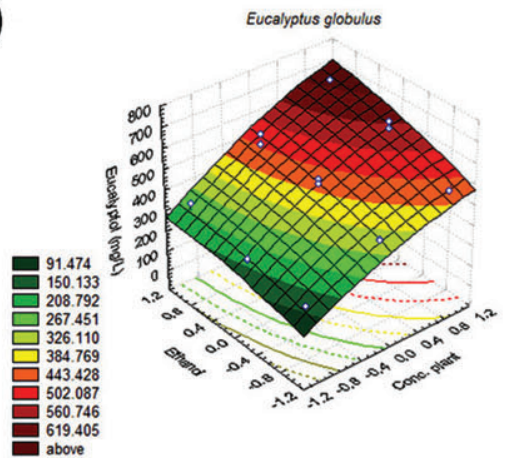

(e)
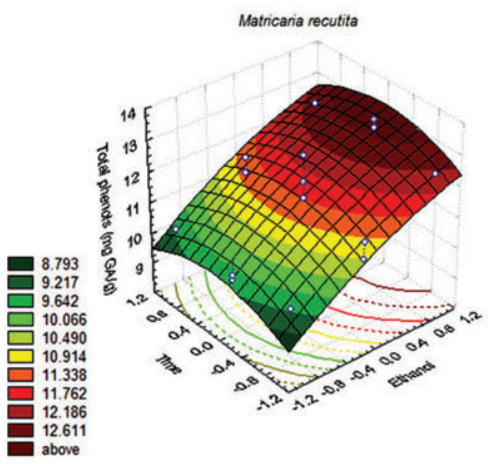

(g)

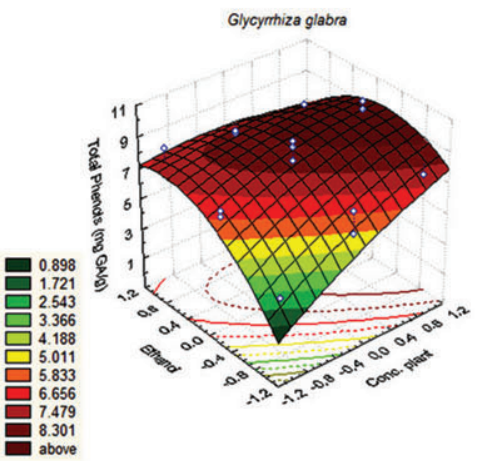

(b)

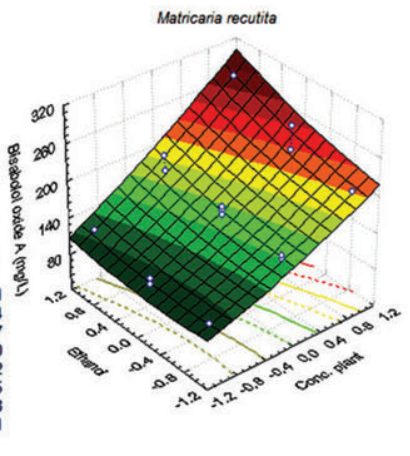

(d)

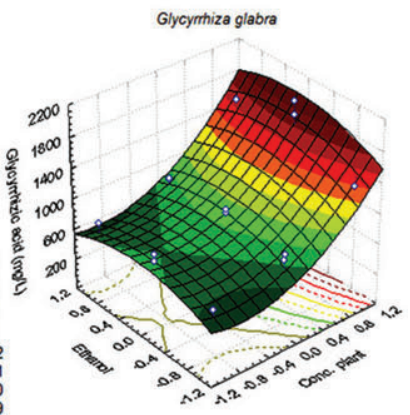

(f)

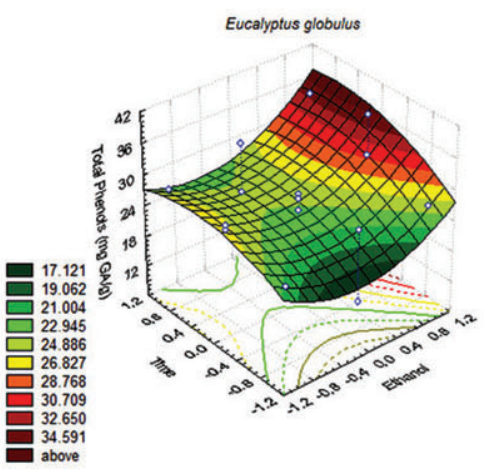

Figure 2. Response surface of principal components and total phenolic content extracted from each plant as a function of the coded concentration of plant and ethanol; time was a fixed intermediate value.

\section{CONCLUSIONS}

Application of a Box-Behnken experimental design for the optimization of plant macerated extraction was shown to be an efficient method for evaluating the effect of concentration of plant, as well as time and ethanol content, on principal compounds, TP and color parameters.

In general, for the main compound and for the consumer valuation of color of each plant macerated, the concentration of plant was the independent variable with a higher positive effect. For
TP and spectrophotometric parameters of color, ethanol content was the independent variable with the highest effect. Time was an independent variable with a lower influence on the extraction of the dependent variables in the present study.

Under optimal conditions, $70 \%\left(\mathrm{v} / \mathrm{v}\right.$ ) of ethanol, $40 \mathrm{~g} \mathrm{~L}^{-1}$ of plant concentration and 3 weeks of maceration, the concentrations of the main compounds observed in the plant macerates that have toxic effects on human health were in the recommendable range. Only eucalyptol content (E. globulus Labill.) was six times greater 
Table 5. Optimized plant macerated conditions according to the mathematical model

\begin{tabular}{|c|c|c|c|c|c|c|}
\hline \multirow[b]{2}{*}{ AMP } & \multirow[b]{2}{*}{ Dependent variables } & \multicolumn{3}{|c|}{ Optimum value for independent variables } & \multicolumn{2}{|c|}{ Optimum value for dependent variables } \\
\hline & & $\begin{array}{l}\text { Plant concentration } \\
\qquad\left(\mathrm{mg} \mathrm{L}^{-1}\right)\end{array}$ & $\begin{array}{l}\text { Time } \\
\text { (weeks) }\end{array}$ & $\begin{array}{c}\text { Ethanol } \\
(\%)\end{array}$ & Predicted & Experimental \\
\hline \multirow[t]{5}{*}{ Coriandrum sativum $\mathrm{L}$. } & Linalool $\left(\mathrm{mg} \mathrm{L}^{-1}\right)$ & 40 & 2.03 & 70 & 173.57 & $154.35 \pm 5.72$ \\
\hline & TP (mg GAE g dry plant ${ }^{-1}$ ) & - & - & - & - & - \\
\hline & $\mathrm{Cl}$ & 40 & 4.7 & 40 & 0.38 & $0.36 \pm 0.02$ \\
\hline & Hue & 10 & 5 & 70 & 10.83 & $10.88 \pm 0.71$ \\
\hline & TCV & 40 & 5 & 40 & 7.27 & $6.89 \pm 0.31$ \\
\hline \multirow[t]{5}{*}{ Matricaria recutita $\mathrm{L}$. } & Bisabolol oxide $\mathrm{A}\left(\mathrm{mg} \mathrm{L}^{-1}\right.$ ) & 40 & 1 & 70 & 269.97 & $276.08 \pm 26.88$ \\
\hline & TP (mg GAE/g dry plant) & 25.38 & 3.15 & 70 & 12.87 & $12.96 \pm 0.32$ \\
\hline & $\mathrm{Cl}$ & 40 & 4.74 & 70 & 0.51 & $0.53 \pm 0.04$ \\
\hline & Hue & 10 & 4.29 & 70 & 14.78 & $14.41 \pm 0.64$ \\
\hline & TCV & 37.48 & 1 & 40 & 7.04 & $6.91 \pm 0.23$ \\
\hline \multirow[t]{5}{*}{ Eucalyptus globulus Labill. } & Eucalyptol (mg L-1) & 40 & 5 & 70 & 665.16 & $922.65 \pm 48.25$ \\
\hline & TP (mg GAE g dry plant ${ }^{-1}$ ) & 10 & 2.11 & 70 & 36.19 & $36.12 \pm 1.12$ \\
\hline & $\mathrm{Cl}$ & 40 & 4.38 & 70 & 0.94 & $0.93 \pm 0.03$ \\
\hline & Hue & 40 & 1 & 70 & 24.45 & $23.12 \pm 0.42$ \\
\hline & TCV & 40 & 1 & 40 & 6.25 & $6.09 \pm 0.21$ \\
\hline \multirow[t]{5}{*}{ Glycyrrhiza glabra L. } & Glycirrhizic acid $\left(\mathrm{mg} \mathrm{L}^{-1}\right)$ & 40 & 1 & 57.52 & 1801.21 & $1812.3 \pm 96.36$ \\
\hline & TP (mg GAE g dry plant ${ }^{-1}$ ) & 40 & 2.66 & 53.12 & 9.04 & $9.02 \pm 0.12$ \\
\hline & $\mathrm{Cl}$ & 40 & 3.66 & 70 & 0.81 & $0.78 \pm 0.04$ \\
\hline & Hue & 40 & 1 & 40 & 24.70 & $22.95 \pm 0.51$ \\
\hline & TCV & 40 & 1 & 40 & 7.74 & $7.69 \pm 0.22$ \\
\hline
\end{tabular}

Table 6. Values for the responses of color parameters: $\mathrm{Cl}$ and hue and consumer tasting color value (TCV)

\begin{tabular}{|c|c|c|c|c|c|c|c|c|c|c|c|c|}
\hline \multirow[b]{3}{*}{ Runs } & \multirow{2}{*}{\multicolumn{3}{|c|}{ Coriandrum sativum $\mathrm{L}$. }} & \multicolumn{3}{|c|}{$\begin{array}{c}\text { Dependent variables } \\
\text { Observed values (predicted values by model) }\end{array}$} & \multirow{2}{*}{\multicolumn{3}{|c|}{ Eucalyptus globulus Labill. }} & \multirow{2}{*}{\multicolumn{3}{|c|}{ Glycyrrhiza glabra L. }} \\
\hline & & & & \multicolumn{3}{|c|}{ Matricaria recutita $\mathrm{L}$. } & & & & & & \\
\hline & $y_{9}: C l$ & $y_{10}:$ Hue & $y_{11}: \mathrm{TCV}$ & $y_{12}: C l$ & $y_{13}:$ Hue & $y_{14}: \mathrm{TCV}$ & $y_{15}: C l$ & $y_{16}:$ Hue & $y_{17}: \mathrm{TCV}$ & $y_{18}: C l$ & $y_{19}:$ Hue & $y_{20}: \mathrm{TCV}$ \\
\hline 1 & $0.05(0.05)$ & $8.26(7.75)$ & $3.4(3.3)$ & $0.10(0.12)$ & $13.33(12.13)$ & $4.7(4.5)$ & $0.15(0.17)$ & $21.34(19.00)$ & $4.0(4.2)$ & $0.18(0.19)$ & $21.24(17.25)$ & $3.3(2.9)$ \\
\hline 2 & $0.19(0.20)$ & $5.46(5.00)$ & $3.6(3.7)$ & $0.37(0.37)$ & $10.51(11.13)$ & $5.5(5.4)$ & $0.54(0.54)$ & $21.55(21.25)$ & $4.2(4.1)$ & $0.70(0.68)$ & $18.74(22.75)$ & $5.1(5.2)$ \\
\hline 3 & $0.08(0.07)$ & $6.90(7.00)$ & $3.2(3.1)$ & $0.13(0.13)$ & $12.39(11.88)$ & $3.5(3.7)$ & $0.23(0.23)$ & $18.63(19.75)$ & $4.2(4.3)$ & $0.23(0.25)$ & $16.70(13.25)$ & $3.3(3.3)$ \\
\hline 4 & $0.29(0.29)$ & $5.80(6.25)$ & $4.5(4.6)$ & $0.43(0.42)$ & $10.31(10.88)$ & $5.2(5.4)$ & $0.68(0.66)$ & $19.05(21.00)$ & $4.2(4.0)$ & $0.72(0.71)$ & $16.66(20.75)$ & $4.3(4.6)$ \\
\hline 5 & $0.12(0.12)$ & $3.92(4.38)$ & $4.8(5.0)$ & $0.09(0.10)$ & $9.50(12.13)$ & $5.6(5.8)$ & $0.14(0.15)$ & $12.68(12.88)$ & $5.3(5.3)$ & $0.14(0.12)$ & $6.90(10.50)$ & $4.5(4.9)$ \\
\hline 6 & $0.38(0.37)$ & $4.25(4.13)$ & $6.7(6.6)$ & $0.24(0.26)$ & $11.98(11.13)$ & $6.8(7.0)$ & $0.30(0.32)$ & $15.04(13.63)$ & $5.9(6.2)$ & $0.54(0.54)$ & $22.91(19.00)$ & $7.7(7.6)$ \\
\hline 7 & $0.06(0.07)$ & $8.82(8.88)$ & $2.9(3.0)$ & $0.14(0.12)$ & $13.90(14.88)$ & $3.4(3.2)$ & $0.31(0.29)$ & $19.43(20.38)$ & $5.2(4.9)$ & $0.28(0.28)$ & $7.07(11.00)$ & $3.2(3.3)$ \\
\hline 8 & $0.19(0.19)$ & $6.42(5.63)$ & $3.4(3.3)$ & $0.51(0.5)$ & $12.02(11.88)$ & $4.9(4.6)$ & $0.92(0.92)$ & $22.80(23.13)$ & $3.7(3.7)$ & $0.78(0.80)$ & $18.51(15.50)$ & $4.6(4.2)$ \\
\hline 9 & $0.24(0.24)$ & $2.53(2.88)$ & $5.4(5.3)$ & $0.19(0.17)$ & $9.35(9.75)$ & $6.9(6.9)$ & $0.21(0.18)$ & $9.42(11.13)$ & $6.0(5.8)$ & $0.32(0.33)$ & $16.38(16.25)$ & $6.6(6.6)$ \\
\hline 10 & $0.25(0.26)$ & $4.70(4.63)$ & $6.1(6.1)$ & $0.19(0.18)$ & $9.19(9.00)$ & $6.8(6.4)$ & $0.25(0.25)$ & $14.72(14.38)$ & $5.8(5.7)$ & $0.36(0.37)$ & $9.50(9.25)$ & $7.0(6.7)$ \\
\hline 11 & $0.09(0.08)$ & $7.33(7.38)$ & $2.9(3.0)$ & $0.28(0.29)$ & $11.56(12.00)$ & $3.9(4.3)$ & $0.53(0.53)$ & $21.72(22.63)$ & $4.2(4.3)$ & $0.54(0.53)$ & $11.00(10.75)$ & $4.1(4.3)$ \\
\hline 12 & $0.17(0.17)$ & $6.00(6.13)$ & $3.0(3.0)$ & $0.30(0.32)$ & $12.71(12.25)$ & $4.0(4.0)$ & $0.61(0.64)$ & $21.58(19.88)$ & $4.2(4.4)$ & $0.60(0.59)$ & $12.35(11.75)$ & $4.1(4.1)$ \\
\hline 13 & $0.18(0.18)$ & $4.74(4.33)$ & $3.6(3.6)$ & $0.28(0.28)$ & $11.17(11.33)$ & $4.8(5.0)$ & $0.48(0.48)$ & $21.49(20.33)$ & $4.3(4.2)$ & $0.51(0.54)$ & $11.12(11.33)$ & $4.3(4.5)$ \\
\hline 14 & $0.19(0.18)$ & $4.47(4.33)$ & $3.8(3.6)$ & $0.28(0.28)$ & $11.00(11.33)$ & $5.2(5.0)$ & $0.47(0.48)$ & $19.90(20.33)$ & $4.1(4.2)$ & $0.54(0.54)$ & $10.82(11.33)$ & $4.7(4.5)$ \\
\hline 15 & $0.18(0.18)$ & $4.38(4.33)$ & $3.5(3.6)$ & $0.29(0.28)$ & $11.84(11.33)$ & $5.0(5.0)$ & $0.49(0.48)$ & $19.71(20.33)$ & $4.1(4.2)$ & $0.56(0.54)$ & $12.43(11.33)$ & $4.5(4.5)$ \\
\hline
\end{tabular}

than the recommended tolerable daily intake value, and so the optimal independent variables must be avoided.

In addition, the model allowed the selection of the conditions of maceration that lead to the color preference appreciated by consumers. It was observed that the experiments with the highest color intensity given by spectrophotometric parameters (hue and
$\mathrm{Cl})$ were not the experiments most valued by consumers. There are numerous factors determining whether the different parts of plants from different species have an influence on the extraction of the different dependent variables.

The results obtained in the present study are a great importance from an industrial point of view because they allow producers to 
(a)

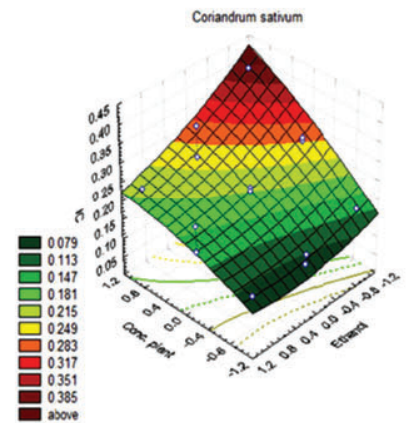

(d)

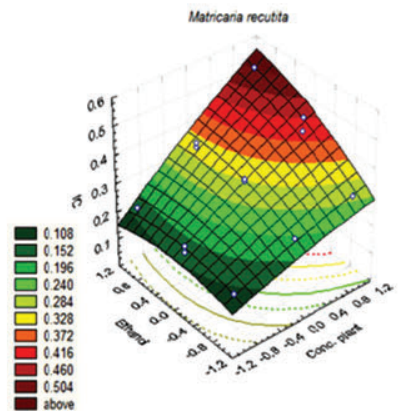

(g)

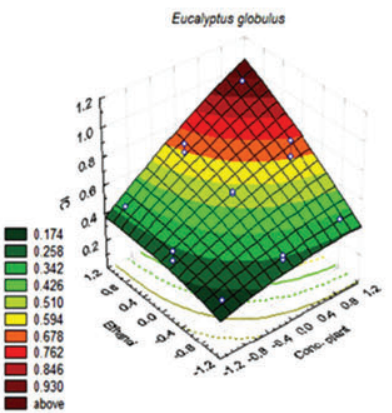

(j)

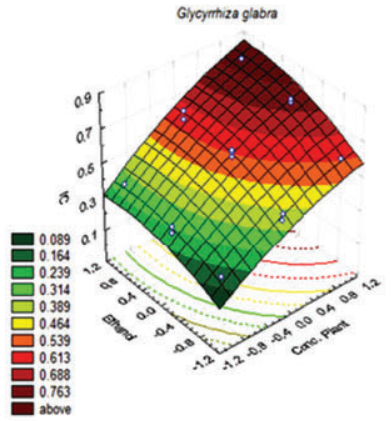

(b)

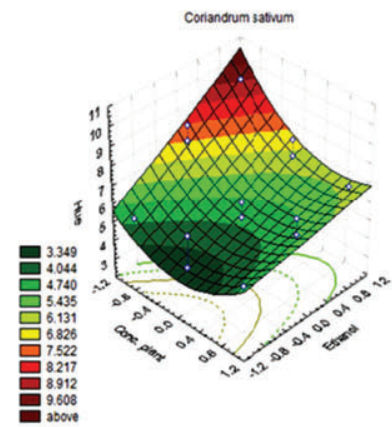

(e)

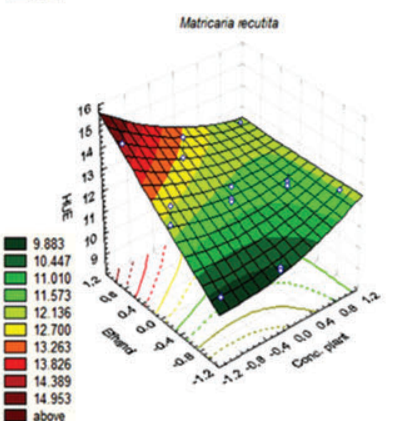

(h)

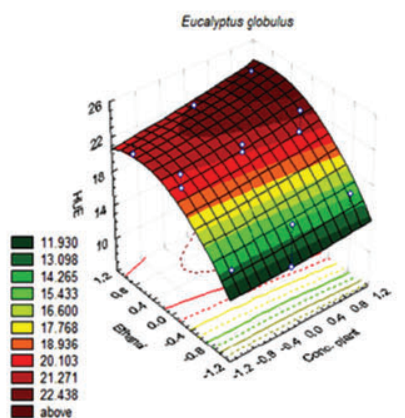

(k)

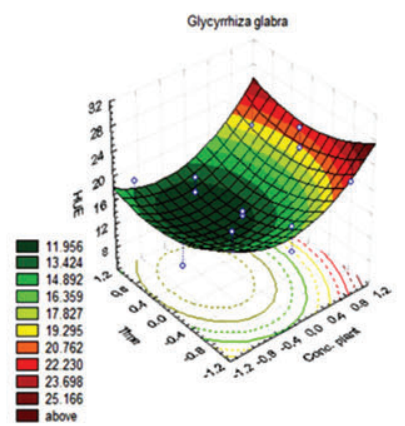

(c)

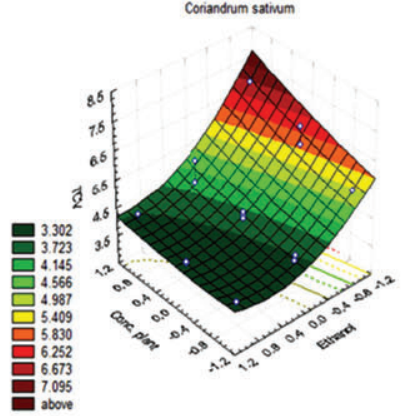

(f)

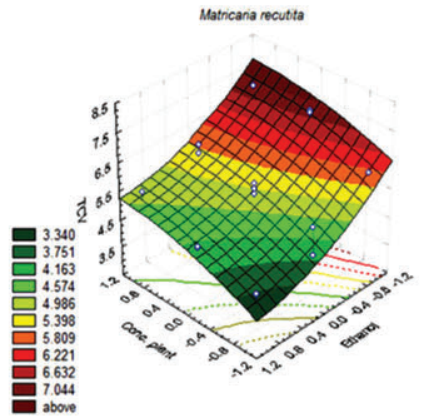

(i)

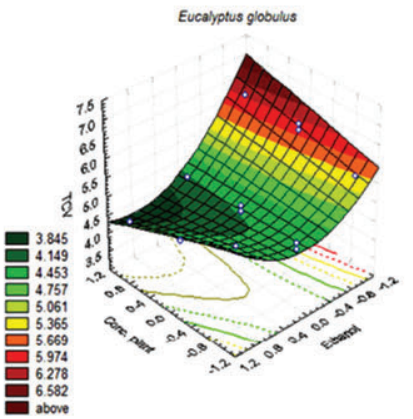

(I)

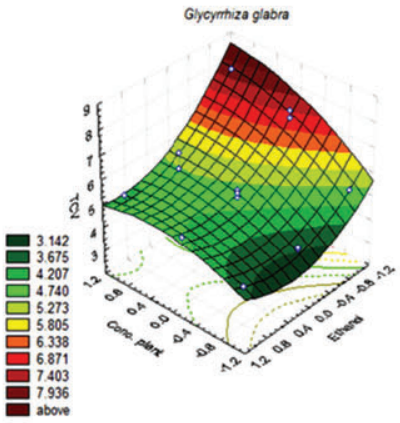

Figure 3. Response surface of color parameters (Color intensity $(\mathrm{Cl})$ and Hue) of each plant extract as a function of dependent variables.

obtain a quick extraction of plant components into spirits using optimal conditions defined previously, thus saving valuable time and money in the production of herbal liqueurs and spirits, as well as avoiding the extraction of negative compounds.

\section{ACKNOWLEDGEMENTS}

We are grateful to the Spanish Ministry of Economy and Competitiveness for financial support of this work (project CTQ2015-71436-C2-1-R), which has received partial financial support from the FEDER funds of the European Union. José Manuel Salgado acknowledges financial support from 'Fundação para a Ciência e Tecnologia $(F C T)^{\prime}$ of Portugal through grant SFRH/BD/87953/2012.

\section{SUPPORTING INFORMATION}

Supporting information may be found in the online version of this article.

\section{REFERENCES}

1 DOG (Official Journal of Galicia). Council Regulation 2012/1/16 on the Definition, Description and Presentation of Geographical Indications Orujo, spirits herbs, herbal liqueur and coffee liqueur from Galicia. Galician Official Paper 10: 2516-2546. 
2 Sashidhara KV, Verma RS and Ram P, Essential oil composition of Matricaria recutita $\mathrm{L}$. from the lower region of the Himalayas. Flavour Frag J 21:274-276 (2006).

3 Can ÖD, Demir Özkay Ü, Kıyan HT and Demirci B, Psychopharmacological profile of Chamomile (Matricaria recutita L.) essential oil in mice. Phytomedicine 19:306-310 (2012).

4 El-Moneim MAA, Fatma SA and Turky AF, Control of Tetranychus urticae Koch by extracts of three essential oils of chamomile, marjoram and Eucalyptus. Asian Pac J Trop Biomed 2:24 (2012).

5 Avonto C, Wang M, Chittiboyina AG, Avula B, Zhao J and Khan IA, Hydroxylated bisabolol oxides, evidence for secondary oxidative metabolism in Matricaria chamomilla. I Natural Products 76:1848-1853 (2013).

6 Eikani MH, Golmohammad F and Rowshanzamir S, Subcritical water extraction of essential oils from coriander seeds (Coriandrum sativum L.). J Food Eng 80:735-740 (2007).

7 Emamghoreishi M, Khasaki M and Aazam MF, Coriandrum sativum, evaluation of its anxiolytic effect in the elevated plus-maze. J Ethnopharmacol 96:365-370 (2005).

8 Coşkuner $\mathrm{Y}$ and Karababa $\mathrm{E}$, Physical properties of coriander seeds (Coriandrum sativum L.). J Food Eng 80:408-416 (2007).

9 Aprotosoaie AC, Hăncianu M, Costache II and Miron A, Linalool, a review on a key odorant molecule with valuable biological properties. Flavour Frag. J 29:193-219 (2014).

10 Fu B, Liu J, Li H, Li L, Lee FS and Wang X, The application of macroporous resins in the separation of licorice flavonoids and glycyrrhizic acid. J Chromatogr A 1089:18-24 (2005).

11 Gray AM and Flatt PR, Antihyperglycemic actions of Eucalyptus globulus (eucalyptus) are associated with pancreatic and extra-pancreatic effects in mice. The J Nutr 128:2319-2323 (1998).

12 Medeiros KC, Monteiro JC, Diniz MF, Medeiros IA, Silva BA and Piuvezam MR, Effect of the activity of the Brazilian polyherbal formulation, Eucalyptus globulus Labill, Peltodon radicans Pohl and Schinus terebinthifolius Radd in inflammatory models. Rev Bras Farmacogn 17:23-28 (2007).

13 Song A, Wang Y and Liu Y, Study on the chemical constituents of the essential oil of the leaves of Eucalyptus globulus Labill from China. Asian J Trad Med 4:34-140 (2009).

14 Đakov T, Antimicrobial effect of essential oil isolated from Eucalyptus globulus Labill. from Montenegro. Czech J Food Sci 29:277-284 (2011).

15 De Vincenzi M, Silano M, De Vincenzi A, Maialetti F and Scazzocchio B, Constituents of aromatic plants, eucalyptol. Fitoterapia 73:269-275 (2002).

16 Gião MS, González-Sanjosé ML, Rivero-Pérez MD, Pereira $\mathrm{Cl}$, Pintado ME and Malcata FX, Infusions of Portuguese medicinal plants, dependence of final antioxidant capacity and phenol content on extraction features. J Sci Food Agr 87:2638-2647 (2007).
17 Rodríguez-Solana R, Salgado JM, Domínguez JM and Cortés-Diéguez $S$, Characterization of fennel extracts and quantification of estragole, optimization and comparison of accelerated solvent extraction and Soxhlet techniques. Ind Crop Prod 52:528-536 (2014).

18 Otles S and Yalcin B, Phenolic compounds analysis of root, stalk, and leaves of nettle. Sci World J 2012:1 -12 (2012).

19 Singh DK, Srivastava B and Sahu A, Spectrophotometric determination of ajmaline and brucine by Folin Ciocalteu's reagent. J Serb Chem Soc 68:685-690 (2003).

20 Ainsworth EA and Gillespie KM, Estimation of total phenolic content and other oxidation substrates in plant tissues using Folin-Ciocalteu reagent. Nat Protoc 2:875-877 (2007).

21 Schirillo JA, Tutorial on the importance of color in language and culture. Color Res App/ 26:179-192 (2001).

22 Bedgood Jr DR, Bishop AG, Prenzler PD and Robards K, Analytical approaches to the determination of simple biophenols in forest trees such as Acer (maple), Betula (birch), Coniferus, Eucalyptus, Juniperus (cedar), Picea (spruce) and Quercus (oak). Analyst 130:809-823 (2005).

23 Saim N, Osman R, Yasin WAHM and Hamid RD, Subcritical water extraction of essential oil from coriander (Coriandrum sativum L.) seeds. Malaysian J Anal Sci 12:35-41 (2008).

24 Mustafa $A$ and Turner $C$, Pressurized liquid extraction as a green approach in food and herbal plants extraction, a review. Anal Chim Acta 703:8-18 (2011).

25 Hinneburg I and Neubert, RHH Influence of extraction parameters on the phytochemical characteristics of extracts from buckwheat (fagopyrum esculentum) herb. J Agric Food Chem 53:3-7 (2005).

26 Dudonne S, Vitrac X, Coutiere P, Woillez M and Merillon JM, Comparative study of antioxidant properties and total phenolic content of 30 plant extracts of industrial interest using DPPH, ABTS, FRAP, SOD, and ORAC assays. J Agric Food Chem 57:1768-1774 (2009).

27 Vongsak B, Sithisarn P, Mangmool S, Thongpraditchote S, Wongkrajang $Y$ and Gritsanapan W, Maximizing total phenolics, total flavonoids contents and antioxidant activity of moringa oleifera leaf extract by the appropriate extraction method. Ind Crop Prod 44:566-571 (2013).

28 Francis FJ, Quality as influenced by color. Food Qual Pref 6:149-155 (1995)

29 Abbott JA, Quality measurement of fruits and vegetables. Postharvest Biol Technol 15:207-225 (1999).

30 Vacca V, Piga A, Del Caro A, Fenu PA and Agabbio M, Changes in phenolic compounds, color and antioxidant activity in industrial red myrtle liqueurs during storage. Nahrung 47:442-447 (2003).

31 Parpinello G P, Versari A, Chinnici F and Galassi S, Relationship among sensory descriptors, cosumer preference and color parameters of Italian Novello red wines. FRes Int 42:1389-1395 (2009). 